Family Medicine and Community Health

\title{
Multimorbidity and oral health: need for new models of care
}

\author{
Balraj Gill, ${ }^{1}$ Andrew Harris, ${ }^{2}$ Christopher Tredwin, ${ }^{2}$ Paramjit Gill ${ }^{3}$
}

To cite: Gill B, Harris A, Tredwin C, et al. Multimorbidity and oral health: need for new models of care. Fam Med Com Health 2020;8:e000387. doi:10.1136/fmch-2020-000387

Received 01 April 2020 Revised 29 August 2020 Accepted 07 September 2020

\section{Check for updates}

(c) Author(s) (or their employer(s)) 2020. Re-use permitted under CC BY-NC. No commercial re-use. See rights and permissions. Published by BMJ.

${ }^{1}$ Royal London Hospital, London, UK

${ }^{2}$ Peninsula Dental School, Plymouth University, Plymouth, UK

${ }^{3}$ Unit of Academic Primary Care, University of Warwick, Coventry, UK

Correspondence to Professor Paramjit Gill; p.gill.1@warwick.ac.uk

\section{ABSTRACT}

Multimorbidity is defined as patients living with two or more chronic health conditions. The prevalence of multimorbidity is increasing, driven by the ageing population, and represents a major challenge to all healthcare systems because these patients are heavy users of services. The link with oral health is growing although there is need for further robust evidence. There is also need for new models of care to address oral health in patients with multimorbidity.

\section{INTRODUCTION}

Multimorbidity is generating increasing interest; it has not been uniformly defined in the past and we have adopted the Academy of Medical Sciences definition '...the coexistence of two or more chronic conditions in the same individual. ${ }^{, 1}$ As worldwide mortality rates decrease combined with an ageing population, the number of people affected by multimorbidity has increased dramatically. $^{2}$ The prevalence of morbidity increases with age with and deprivation with people in deprived areas having the same prevalence of multimorbidity as more affluent patients who were $10-15$ years older. $^{13}$

Expenditure on healthcare rises almost exponentially with the number of chronic disorders that an individual has, so increasing multimorbidity generates financial pressures. This economic burden heightens the need to manage people with several chronic illnesses in more efficient ways. ${ }^{45}$

In a systematic analysis of global burden, ${ }^{6}$ oral conditions were deemed endemic, affecting 3.9 billion people worldwide. Despite being largely preventable, dental caries was found to have the highest prevalence (35\% globally) of the 291 included conditions; severe periodontitis, and severe tooth loss were sixth, and thirty-sixth, respectively, while oral cancer is the eleventh most common malignancy worldwide. ${ }^{7}$

Perhaps unsurprisingly, WHO considers oral conditions a major public health problem; ${ }^{8}$ inextricably linked to overall health, poor oral health can lead to infection and pain and can have a subtle effect on well-being such as sleep, work and social confidence. ${ }^{9}$ While oral health conditions are not primarily viewed as life-threatening conditions, ${ }^{10}$ those with poor oral health have a significant association with higher mortality. ${ }^{11}$

While oral conditions often have shared risk factors with other chronic conditions, it has been hypothesised that oral diseases, such as periodontitis, may contribute to a proinflammatory state. ${ }^{12}$ This may play a part in accelerating or exacerbating conditions related to chronic conditions, such as cardiovascular disease, which in 2016 accounted for 17.9 million deaths globally. ${ }^{13} 14$

\section{ASSOCIATION BETWEEN ORAL HEALTH AND GENERAL HEALTH}

For the past three decades there has been and increasing focus on the relationship between oral disease and other commonly found medical diseases. The majority of the literature has focused on periodontitis ${ }^{15}$ and its relationship with other systemic inflammatory diseases, although no cause-effect relationships have been widely accepted. ${ }^{16}$

Disentangling a cause-effect relationship from shared risk factors has been problematic due to study design challenges, though indirect evidence suggests an independent relationship between periodontal disease and conditions such as type 2 diabetes, rheumatoid arthritis, cardiovascular disease, Parkinson's disease, psoriasis, respiratory infections and Alzheimer's disease, among others. ${ }^{16}$

There continues to be emerging evidence that oral health plays a role in general chronic diseases. In particular, periodontal disease and diabetes mellitus have been described as having a 'bi-directional' relationship, meaning glycaemic control affects a person's periodontal status, and vice versa. Studies have shown that people with diabetes who have severe gum disease-characterised as bleeding gums, gingival recession, tooth mobility and alveolar bone loss-also have higher HbAlc levels compared with those with healthier gums. ${ }^{17}$ One study indicated 
that non-surgical periodontal treatment significantly improved metabolic control in patients with type 2 diabetes. ${ }^{18}$ Conversely, raised levels of advanced glycation end products in patients with poorly controlled diabetes may result in production of proinflammatory cytokines. These cytokines in turn can induce periodontal tissue destruction. $^{19}$

Indeed, periodontal disease has been shown to have associations with many other diseases. These include increased risk of heart attack or stroke, independent of the other well-known cardiovascular risk factors. Indirect mechanisms such as systemic inflammation have been proposed, with increased levels of inflammatory protein as found in patients with periodontitis, also being predictors of future cardiac events. ${ }^{20}$ It has also been suggested that direct mechanisms such as bacteraemia and vascular infection from periodontal pathogens may contribute to aortic vasculopathy. ${ }^{21}$ A direct cause-effect relationship was suggested in a PAROKRANK Study ${ }^{22}$ and a significant risk of first-time myocardial infarction was found in patients with periodontitis, this risk remaining significant even after adjustments were made for risk factors such as smoking and diabetes. The expectation that periodontal treatment would therefore reduce the risk of cardiovascular events has not materialised however, with little evidence found in a recent umbrella review that non-surgical therapy reduces the risk of cardiovascular events. $^{23}$

Furthermore, in some at-risk populations, poor oral health and periodontitis may be associated with certain respiratory conditions including pneumonia and chronic obstructive pulmonary disease (COPD). Typical respiratory pathogens have been shown to colonise the dental plaque of hospitalised intensive care and nursing home patients ${ }^{24}$ and it has been suggested that these pathogens may then become aspirated into the lungs and cause infection. One study reported that alveolar bone loss was an independent risk factor for COPD, supporting a possible role of periodontal disease in the pathogenesis of COPD or its progression. ${ }^{25}$

Further, maternal periodontal disease and low birth weight of infants has been shown to have an association. ${ }^{9}$ Once again, it has been postulated that bacterial migration from periodontal tissues into blood circulation may stimulate the production of inflammatory mediators.

\section{RISK FACTORS}

One of the greatest risk factors is age-related deterioration of the oral tissues and a higher probability of systemic illness. ${ }^{26}$ As populations age, maintaining oral care becomes problematic and gingival recession and root caries becomes more prevalent. ${ }^{27}$ It has been estimated that in India almost half of those aged 75 years have an experience of root caries, ${ }^{28}$ which is a major cause of tooth loss. ${ }^{27}$ In the USA tooth loss increases with age and almost $19 \%$ of seniors (over 65 years) are edentulous. ${ }^{29}$ Tooth loss has a significant effect on well-being, and has been related to a decline in nutrition and health, as food preferences move away from fresh vegetables and fruits towards softer foods. ${ }^{29}$ Further, edentulous patients who retain their dental prosthesis overnight have increased risk of pneumonia. ${ }^{30}$

The decline in oral health in an ageing population has been linked to the side effects of polypharmacy related to chronic conditions. A plethora of commonly prescribed medications can induce hyposalivation, which increases the risk of oral disease including caries, periodontal disease and candidiasis. ${ }^{31}$

Certain chronic conditions which are more prevalent in the elderly can lead to a reduction in cognitive or motor skills. Patients with dementia can be reluctant to remove their dentures at night, which can lead to denture stomatitis. Additionally other progressive neurological disorders such as Parkinson's disease can affect motor function and has been associated with a greater risk of caries and periodontal disease. ${ }^{26}$

Risk factors are not confined to an ageing population and the burden is greatest on those from low socioeconomic backgrounds, not least because WHO says treatment of oral disease is costly, the fourth most expensive disease to treat in many countries. ${ }^{8}$

Stress, hygiene and trauma as well as the more common risk factors like unhealthy diet, smoking and alcohol consumption have been implicated ${ }^{32}$; therefore oral health improvement is not just in its treatment, but also prevention. However, in developing countries where oral health expenditure is already low, resources are largely focused on treatment of acute symptoms and emergency care. It is estimated that if treatment and preventative measures were widely available, the cost of dental caries for children alone would exceed total child healthcare expenditure. ${ }^{33}$ As a consequence, in many countries there are a number of difficulties in overcoming untreated dental disease.

In terms of risk factors, many are shared between oral and general chronic problems like diabetes and cardiovascular disease. These common modifiable factors usually relate to lifestyle habits. It is a well-established fact that smoking cigarettes increases the risk of lung cancer, but it also increases the risk of tooth loss as a result of periodontal disease. ${ }^{34}$ Therefore, there is an association between oral diseases and non-communicable diseases and by addressing these factors, the positive impact on the population would be significant.

\section{CONCLUSION}

It appears that many populations globally are experiencing multimorbidity and the available evidence about the burden, determinants, prevention and treatment of patients with multimorbidity is inadequate. Research gaps need to be filled across a wide range of perspectives from biological mechanisms to healthcare systems management. ${ }^{1}$

In the meantime, implementation of public health measures in order to reduce exposure to risk factors is 
key in reducing the burden of oral disease, and at the same time general diseases. It is likely that health inequalities must be addressed in order for factors like sugar consumption, alcohol and smoking use to decrease. ${ }^{31}$ In terms of dental conditions, the disease process is largely avoidable, and as such prevention should be at the forefront of tackling this issue. This needs coordination and delivery by all health professionals as well as statutory and third sector organisations.

Contributors $P G$ and $B G$ conceived the idea that was developed by all the authors. $B G$ wrote the first draft with critical inputs from PG, AH, CT.

Funding The authors have not declared a specific grant for this research from any funding agency in the public, commercial or not-for-profit sectors.

Competing interests None declared.

Patient consent for publication Not required.

Provenance and peer review Not commissioned; externally peer reviewed.

Open access This is an open access article distributed in accordance with the Creative Commons Attribution Non Commercial (CC BY-NC 4.0) license, which permits others to distribute, remix, adapt, build upon this work non-commercially, and license their derivative works on different terms, provided the original work is properly cited, appropriate credit is given, any changes made indicated, and the use is non-commercial. See: http://creativecommons.org/licenses/by-nc/4.0/.

\section{REFERENCES}

1 Academy of Medical Sciences. Multimorbidity: a priority for global health research April 2018. Available: https://acmedsci.ac.uk/filedownload/99630838 [Accessed 4 Jun 2020].

2 Navickas R, Petric V-K, Feigl AB, et al. Multimorbidity: what do we know? what should we do? J Comorb 2016;6:4-11.

3 Formiga F, Ferrer A, Sanz H, et al. Patterns of comorbidity and multimorbidity in the oldest old: the Octabaix study. Eur $J$ Intern Med 2013;24:40-4.

4 Hajat C, Stein E. The global burden of multiple chronic conditions: a narrative review. Prev Med Rep 2018;12:284-93.

5 Salive ME. Multimorbidity in older adults. Epidemiol Rev 2013;35:75-83.

6 Marcenes W, Kassebaum NJ, Bernabé E, et al. Global burden of oral conditions in 1990-2010: a systematic analysis. J Dent Res 2013;92:592-7.

7 Ghantous Y, Abu Elnaaj I, Elnaaj A I. [Global incidence and risk factors of oral cancer]. Harefuah 2017;156:645-9.

8 Petersen PE. The World Oral Health Report 2003: continuous improvement of oral health in the 21st century--the approach of the WHO Global Oral Health Programme. Community Dent Oral Epidemiol 2003;31:3-24.

9 Australian Health Ministers' Conference, National Advisory Committee on Oral Health. Healthy mouths, healthy lives: Australia's national oral health plan 2004-13. Adelaide: South Australian Department of Health, 2004.

$10 \mathrm{Kim}$ JK, Baker LA, Davarian S, et al. Oral health problems and mortality. J Dent Sci 2013;8:115-20.
11 Jansson L, Lavstedt S, Frithiof L. Relationship between oral health and mortality rate. J Clin Periodontol 2002;29:1029-34.

12 Cardoso EM, Reis C, Manzanares-Céspedes MC. Chronic periodontitis, inflammatory cytokines, and interrelationship with other chronic diseases. Postgrad Med 2018;130:98-104.

13 World Health Organisation. Cardiovascular diseases. Available: https://www.who.int/news-room/fact-sheets/detail/cardiovasculardiseases-(cvds) [Accessed 4 Jun 2020]

14 Nicholson K, Makovski TT, Griffith LE, et al. Multimorbidity and comorbidity revisited: Refining the concepts for international health research. J Clin Epidemiol 2019;105:142-6.

15 Seitz MW, Listl S, Bartols A, et al. Current knowledge on correlations between highly prevalent dental conditions and chronic diseases: an umbrella review. Prev Chronic Dis 2019;16:E132.

16 Holmstrup P, Damgaard C, Olsen I, et al. Comorbidity of periodontal disease: two sides of the same coin? an introduction for the clinician. J Oral Microbiol 2017;9:1332710.

17 European Federation of Periodontology.. Diabetes and gum disease. Available: https://www.bsperio.org.uk/publications/downloads/65_ 091416 diabetes-gum-disease.pdf. [Accessed 4 Jun 2020].

18 Corbella S, Francetti L, Taschieri S, et al. Effect of periodontal treatment on glycemic control of patients with diabetes: a systematic review and meta-analysis. J Diabetes Investig 2013;4:502-9.

19 Brownlee M. Biochemistry and molecular cell biology of diabetic complications. Nature 2001;414:813-20.

20 Loos BG, Craandijk J, Hoek FJ, et al. Elevation of systemic markers related to cardiovascular diseases in the peripheral blood of periodontitis patients. J Periodontol 2000;71:1528-34.

21 Roth GA, Moser B, Roth-Walter F, et al. Infection with a periodontal pathogen increases mononuclear cell adhesion to human aortic endothelial cells. Atherosclerosis 2007;190:271-81.

22 Rydén L, Buhlin K, Ekstrand E, et al. Periodontitis increases the risk of a first myocardial infarction: a report from the PAROKRANK study. Circulation 2016;133:576-83.

23 Lavigne SE, Forrest JL. An umbrella review of systematic reviews of the evidence of a causal relationship between periodontal disease and cardiovascular diseases. Can J Dent Hyg 2020;54:32-41.

24 Scannapieco FA. Role of oral bacteria in respiratory infection. $J$ Periodontol 1999;70:793-802.

25 Leuckfeld I, Obregon-Whittle MV, Lund MB, et al. Severe chronic obstructive pulmonary disease: association with marginal bone loss in periodontitis. Respir Med 2008;102:488-94.

26 Critchlow D. Part 3: impact of systemic conditions and medications on oral health. Br J Community Nurs 2017;22:181-90.

27 Gati D, Vieira AR. Elderly at greater risk for root caries: a look at the multifactorial risks with emphasis on genetics susceptibility. Int $J$ Dent 2011;2011:1-6.

28 Ingle NA, Chaly PE, Kayamali Zohara C. Oral health related quality of life in adult population attending the outpatient department of a hospital in Chennai, India. J Int Oral Health 2010;2:45-55.

29 Raphael C. Oral health and aging. Am J Public Health 2017;107:S44-5.

30 linuma T, Arai Y, Abe Y, et al. Denture wearing during sleep doubles the risk of pneumonia in the very elderly. J Dent Res 2015;94:28S-36.

31 Hopcraft MS, Tan C. Xerostomia: an update for clinicians. Aust Dent J 2010;55:238-44.

32 Sheiham A. Dietary effects on dental diseases. Public Health Nutr 2001;4:569-91.

33 Yee R, Sheiham A. The burden of restorative dental treatment for children in third World countries. Int Dent J 2002;52:1-9.

34 Tomar SL, Asma S. Smoking-attributable periodontitis in the United States: findings from NHANES III. National health and nutrition examination survey. J Periodontol 2000;71:743-51. 